\title{
Editorial
}

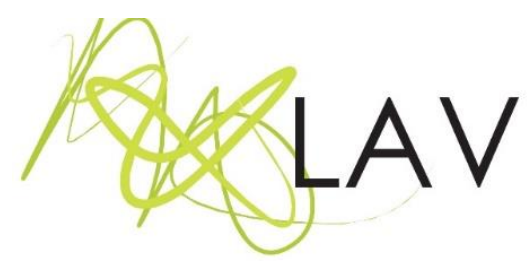

Revista Digital do LAV - Laboratório de Artes Visuais - vol. 10, n.3, set./dez. 2017. Universidade Federal de Santa Maria, RS, Brasil.

ISSN: $1983-7348$

Caros leitores e caras leitoras,

É com imensa satisfação que apresentamos o terceiro número do volume dez da Revista Digital do LAV deste ano. Fechamos assim o ano de 2017 com mais de 30 artigos publicados. $\mathrm{E}$, nesse sentido, somos muito gratas a todos vocês autores e autoras que nos escolheram e decidiram publicar conosco. Obrigada!

Este último número do ano, para além de uma coletânea de excelentes artigos, traz algumas novidades: a padronização das capas, várias seções traduzidas para a língua inglesa, o lançamento do tema do dossiê para 2019 "Pesquisa (com) arte (na) docência", pois o de 2018 "Narrativas afetivas de professores de artes: experiências poéticas e educação docente" já está aberto e recebendo artigos até 30 de maio de 2018. Ou seja, temos motivos de sobra para comemorar o encerramento deste ano e muitos planos para o futuro.

Este número traz 12 contribuições de pesquisadores de universidades brasileiras e estrangeiras: UERJ, UDESC, UFSJ, UEL, UFPE, UNIFESP, UNIVILLE, UFBA, UDESC, UEM, Universidad de Barcelona - Espanha, Universidad de la República - Uruguai e UFSM.

Em Caminhos de uma pesquisa: a costurografia como outra escrita acadêmica, Anelice Ribetto e Rejane Nascimento, professoras da Universidade Estadual do Rio de Janeiro (UERJ), apresentam-nos uma pesquisa que tem apostado em problematizar a escrita acadêmica como empreitada coletiva, como aposta política, ética e estética. A costurografia como manualidade, como um dispositivo, busca forjar encontros, conversar, deformar e experienciar novas possibilidades em relação à escrita acadêmica.

Camila Barbosa, acadêmica do curso de Geografia (Licenciatura) na Universidade do Estado de Santa Catarina (UDESC) e Ana Maria Hoepers Preve, professora da mesma instituição de ensino, em Geografias em deriva, oferecem-nos uma investigação que busca apresentar as derivas do trabalho realizado no Hospital de Custódia e Tratamento Psiquiátrico de Florianópolis (HCTP) com os internos, através das práticas desenvolvidas nas oficinas 'Geografias em Deriva'. Essas oficinas têm investido em pensar sobre o caminhar e o escrever, sobre o contato com o mundo através de uma

Revista Digital do LAV - Santa Maria - vol. 10, n. 3, p. 1 - 4 - set./dez. 2017 ISSN 1983 - 7348

http://dx.doi.org/10.5902/1983734830529 
experiência que envolve, necessariamente, uma superfície, um chão, um território.

Fernanda Walter Omelczuk, professora da Universidade Federal de São João del Rei (UFSJ), brinda-nos com o texto Cinema no hospital? Hipóteses, experimentações e aprendizagens de uma pesquisa, onde discute a questão da Educação e o Cinema em um espaço fora da escola. No seu artigo, a autora apresenta a pesquisa do projeto de extensão - Cinema no hospital? - que acontece há sete anos em um hospital pediátrico universitário, destacando as contribuições dessa atividade para a prática docente, a infância e os diferentes adultos que atravessam o território hospitalar.

\section{Transcriação e formação em arte a partir da obra fotográfica de} José Juliani, de Fernando Amaral Stratico e Ronaldo Alexandre de Oliveira, professores da Universidade Estadual de Londrina (UEL), buscam apresentar no seu texto a obra fotográfica de José Juliani como construção e investigação no campo da fotografia que refletem modos de conceber o ser humano e sua relação com o meio. A criação artística a partir da obra de Juliani reforça novos paradigmas da pesquisa em arte que possuem reverberações e implicações diretas no campo da formação artística.

As autoras Maísa Gomes Sobral e Márcia Regina Barbosa (UFPE) nos apresentam a pesquisa: Os desenhos de uma criança da Escolinha de Arte do Recife: o olhar artístico em meio às imagens cinematográficas e às séries televisivas. Este estudo objetivou compreender como a criança significa os desenhos criados por ela a partir da visualidade de imagens de filmes e de séries televisivas.

Em Acerca da ética no campo da formação e no trabalho em equipe, a autora Adriana Barin Azevedo (UNIFESP), conta-nos sobre um trabalho que desenvolveu em um dos módulos curriculares de uma formação interdisciplinar para seis cursos da área da saúde a partir do pensamento de Espinosa e Deleuze, a respeito da diferenciação entre ética e moral na experiência de trabalho em equipe e com coletivos. Este texto apresenta questões para pensar em outras práticas interessadas na discussão da postura ética nas relações entre campos de saber distintos.

Dalva Maria Alves Alcântara e Nadja de Carvalho Lamas (UNIVILLE) nos presenteiam com o texto Redemoinho infinito: Schwanke e seu livro de artista, onde exploram o conceito de arquivo sob a perspectiva de Jacques Derrida, em seu "Mal de Arquivo - Uma impressão freudiana", a partir da análise do Livro de Artista de Luiz Henrique Schwanke. A partir dessa obra, uma série de pinturas conformadas num livro objeto de arte, um "livro de artista", serão feitas ponderações quanto à significância do arquivamento como um recurso na poética do artista.

Revista Digital do LAV - Santa Maria - vol. 10, n. 3, p. 1 - 4 - set./dez. 2017 ISSN 1983 - 7348

http://dx.doi.org/10.5902/1983734830529 

Estágio Docente, Desenho e Símbolo: tríade para investigar e
compreender corporeidades afro-brasileiras, texto apresentado por Eduardo Oliveira Miranda (UFBA), discute uma experiência docente do componente curricular Estágio Docente. Eduardo trabalhou com as categorias de Desenho, Imagem e Símbolo com a prerrogativa de compreender a realidade dos educandos a partir da projeção gráfica e como eles podem explicar as suas intersubjetividades através dos traços e linhas. Nesse cenário, criaram-se desenhos elucidativos das populações negras o que proporcionou as discussões sobre as corporeidades afro-brasileiras.

Luzinete Carpin Niedzieluk (UDESC), escreve sobre a importância da Ação Educativa em Espaços Culturais para a formação inicial e continuada de professores de arte e destaca a interação dos estudantes com as equipes educativas de instituições culturais de Florianópolis, pesquisadores da arte, do ensino de arte e da mediação cultural. A autora apresenta-nos neste texto, uma Mostra de Artes Visuais organizada pelos próprios estudantes e os conceitos que envolvem tal prática, como por exemplo: organização, curadoria, museografia, montagem e mediação.

João Paulo Baliscei e Geiva Carolina Calsa da Universidade Estadual de Maringá juntamente com Fernando Herraiz García, da Universidad de Barcelona escrevem juntos o texto Imagens da Disney (re)produzindo gênero: revisão da produção acadêmica (2003-2015). Os autores investigam a produção científica brasileira da última década no que diz respeito às relações entre as imagens da Disney, educação e gênero. As nove pesquisas localizadas foram divididas em três grupos: um reunindo os artigos de periódicos científicos; outro, os estudos desenvolvidos junto a Programas de Pós-Graduação de História, Letras, Antropologia e Estudos Culturais; e outro, os elaborados em Programas de Pós-Graduação em Educação. Em comum, aproximam a Disney a contextos de aprendizagens e denunciam as maneiras como seus produtos sugerem construções específicas de gênero, sobretudo, em relação à feminilidade.

Visualidades e identidades adolescentes. Reflexiones en torno a un proyecto de investigación é a pesquisa de Gonzalo Vicci Gianotti da Escuela Nacional de Bellas Artes da Universidad de la República, Uruguai. Neste artigo Gonzalo se propõe a pensar no trabalho realizado em cinco escolas do ensino médio de Montevidéu, nos anos 2015 e 2016. O pesquisador analisa como se constroem as imagens dos corpos adolescentes relacionando-os com as artes e os meios visuais.

E finalmente, encerramos este número com o texto dos autores Rogério Vanderlei de Lima Trindade e Marcelo de Andrade Pereira (UFSM), A dimensão relacional da arte do presente no presente do ensino da arte, onde discutem as ações-coletivas presentificadas no âmbito da arte, tomadas como dispositivo da arte do agora. Discorrem também sobre como o cotidiano se manifesta nas proposições artísticas inseridas ou não nas abordagens do ensino da arte. O artigo sinaliza para uma forma de produção estética que implica aproximar o sujeito com os novos enunciados acerca de

Revista Digital do LAV - Santa Maria - vol. 10, n. 3, p. 1 - 4 - set./dez. 2017 ISSN 1983 - 7348

http://dx.doi.org/10.5902/1983734830529 
si e da arte surgidos na contemporaneidade. O texto trabalha com o conceito de estética relacional, procurando estreitar a relação entre a experiência estética e dispositivos relacionais de arte, inserido e atualizado no contexto educacional.

Desejamos aos nossos leitores e leitoras uma arejada e inspiradora leitura.

Editoras

Marilda Oliveira de Oliveira

Vivien Kelling Cardonetti 